\title{
A ETNOGRAFIA NO QUILOMBO: APROXIMAÇÕES E EXPERIÊNCIAS A PARTIR DE UMA PESQUISA ANTROPOLÓGICA COM MIGRANTES QUILOMBOLAS NO RS
}

\author{
Cristiano Sobroza Monteiro ${ }^{1}$ \\ Maria Catarina Chitolina Zanini
}

\section{A ideia do estrangeiro}

\begin{abstract}
Suponhamos que eu tivesse levado três, no máximo cinco minutos para apanhar a mochila, essa bagagem típica e mínima de quem não se importa de andar de lá para cá o tempo todo sem paradeiro, saltar do trem e subir as escadas da plataforma até o corredor de saída, naquele passo meio desconfiado dos recém-chegados a algum lugar onde nunca estiveram antes. (Abreu, 2002, p. 17).
\end{abstract}

No conto Bem longe de Marienbad, que compõe a obra Estranhos estrangeiros, de Caio Fernando Abreu (2002), há evidências da construção e afirmação da identidade do sujeito que se exila voluntariamente, que, em uma nova relação espaço-temporal, tem de criar novas situações de existência nesse espaço. Esse conto se passa em SaintNazaire, na França, onde o narrador-viajante desembarca solitário em uma estação de trem, somente com sua mochila e seu olhar, e inicia um relato de viagem mostrando seu antagônico desejo de ser reconhecido em terra estrangeira. Em meio a pensamentos e ações, vontades e algumas realizações, o relato do viajante se dá na busca por K., um provável amor que, durante a narrativa, representa a constante ausência. Um dos pontos centrais do conto é: como podemos existir no espaço entre-lugar, ou seja, quem é esse sujeito de destino itinerante, que encontra no deslocamento a acolhida, que persiste em buscar e construir presenças a fim de preencher ausências, que se reconhece enquanto um ser em permanente trânsito e que aceita, no final de tudo, o provisório como lar? (Pires, 2007).

Desde 2008, Monteiro realizou atividades de bolsista do Curso de Ciências Sociais da Universidade Federal de Santa Maria (UFSM), no Projeto Técnico de Identificação e Delimitação ${ }^{3}$, que visava à construção de um laudo antropológico ${ }^{4}$ no

\footnotetext{
${ }^{1}$ Universidade de Caxias do Sul, Brasil.

${ }^{2}$ Universidade Federal de Santa Maria, Brasil.

${ }^{3}$ O projeto foi possível a partir de uma parceria firmada entre o Instituto Nacional de Colonização e Reforma Agrária (Incra) e a Universidade Federal de Santa Maria (UFSM). O Curso de Ciências Sociais,
} 
sentido de reconhecer direitos aos descendentes de escravos da comunidade remanescente do quilombo ${ }^{5}$ Arnesto Penna Carneiro, localizado em Palma, oitavo distrito de Santa Maria ${ }^{6}$, RS.

A aproximação a esse objeto se deu, justamente, pela participação de Monteiro em uma equipe interdisciplinar ${ }^{7}$ que produziu um laudo antropológico que apontava para a possibilidade de reconhecimento de direitos aos descendentes de escravos. A comunidade quilombola Arnesto Penna Carneiro, desde 2007, vem passando por um processo de regulamentação fundiária, visando à garantia de direitos constitucionais, sobretudo territoriais ${ }^{8}$, aos quilombolas ${ }^{9}$. Sua inserção como pesquisador no quilombo situava-se nesse contexto de reivindicações por direitos legais.

Em decorrência dos trabalhos de campo realizados nesse período e de um processo de mobilização construído por diversos agentes políticos e, principalmente, pelo Movimento Negro de Santa Maria e pela UFSM, os moradores da comunidade tiveram de articular a sua condição quilombola com elementos da tradição e com a constituição de novos sujeitos políticos e de direitos, em um processo de inclusão e visibilidade social, processo este que já está em curso no quilombo.

Realizar uma pesquisa com migrantes fez com que Monteiro se percebesse por vezes como um "estrangeiro", primeiramente, pelo próprio ato de deslocar-se; segundo, pelo sentimento de incerteza gerado pelo desconhecido. Faltavam-lhe os referencias do lugar de origem e as relações habituais com as pessoas próximas, tinha a sensação de ser um estrangeiro, um viajante adentrando em um lugar pouco conhecido. Foi no diálogo

por meio da Prof. ${ }^{a}$ Dr. ${ }^{a}$ Maria Catarina Chitolina Zanini, indicou dois alunos graduandos que tivessem interesse na temática, sendo que eu fui um deles, juntamente com Raoni da Rosa.

${ }^{4} \mathrm{O}$ laudo é o resultado final de uma perícia. Na área de antropologia, a perícia constitui-se em uma investigação sobre um determinado grupo ou indivíduo enquanto culturalmente posicionado. Então, o antropólogo é chamado a responder a alguns quesitos elaborados por um juiz ou instituição. Esses quesitos poderão ser esclarecedores de dúvidas, orientar ou criar alguns parâmetros que dizem respeito à dimensão cultural da vida social (Leite, 2004).

5 As categorias "comunidade", "comunidade quilombola" ou "quilombo", utilizadas neste artigo, referemse ao mesmo objeto, a comunidade quilombola Arnesto Penna Carneiro.

${ }^{6}$ A cidade de Santa Maria se localiza na região central do Rio Grande do Sul e a sua população é de 261.031 habitantes (IBGE, 2011). Tem como um de seus distritos Palma, que está localizado no extremo oeste do município e faz fronteira com Restinga Seca. É lá que está localizada a comunidade de remanescentes quilombolas Arnesto Penna Carneiro.

7 A equipe era composta por uma antropóloga, um geógrafo, um advogado, lideranças do movimento negro, além de alunos pesquisadores das áreas acima citadas e funcionários da própria UFSM.

${ }^{8}$ Ver Almeida (2005).

${ }^{9}$ De acordo com o Art. 68 do Ato das Disposições Constitucionais Transitórias (ADCT) da Constituição Brasileira de 1988: aos remanescentes das comunidades dos quilombos que estejam ocupando suas terras é reconhecida a propriedade definitiva, devendo o Estado emitir-lhes os títulos respectivos. 
com Maria Catarina Zanini, enquanto orientadora acadêmica, que surgiram alguns pontos de convergência para a pesquisa.

Em $O$ estrangeiro, Simmel (2005) problematiza a categoria do estrangeiro para pensar na relação entre o próximo e o distante entre grupos sociais. O autor se questiona: se se mover é libertar-se de qualquer ponto definido no espaço e é, assim, opor-se à fixação nesse ponto, o "estrangeiro" representa, nesse sentido, a unidade de ambas as disposições? A partir do duplo, fixação/libertação, o autor destaca como os viajantes mercadores, entendidos como estrangeiros, não eram mais indivíduos "que chegam hoje e partem amanhã, porém, eram pessoas que chegavam hoje e amanhã ficavam" (Simmel, 2005, p. 1). Nesse sentido, a oposição entre o nós e o estrangeiro é determinada pelo fato de este não ter pertencido àqueles desde o começo, pelo fato de o estrangeiro ter introduzido qualidades que não se originaram nem poderiam se originar no próprio grupo. A unificação de proximidade e distância envolvida em toda relação humana organiza-se no fenômeno do estrangeiro, a distância significa que ele, que está próximo, está distante; e a condição de estrangeiro significa que ele, que também está distante, na verdade está próximo, pois ser um estrangeiro é "naturalmente uma relação muito positiva: é uma forma específica de interação" (Simmel, 2005, p. 1).

O estrangeiro também é retratado por Alfred Schütz (2003), que, partindo de uma teoria geral da interpretação, estuda a situação em que um estrangeiro se encontra no esforço de interpretar o padrão cultural de um determinado grupo social para orientar-se dentro dele. Por "estrangeiro", o autor compreende um indivíduo adulto de nosso tempo e civilização que tenta ser permanentemente aceito ou ao menos tolerado pelo grupo do qual ele se aproxima. A tentativa do autor está em mostrar como o padrão de vida ${ }^{10}$ de um grupo apresenta-se para o senso comum do homem que vive seu cotidiano dentro do grupo com seus semelhantes. Qualquer membro nascido ou criado dentro desse grupo aceita o esquema já pronto e estandardizado do padrão cultural legado a ele pelos ancestrais, pelos professores e autoridades como inquestionado e inquestionável guia em todas as situações que ocorrem normalmente no mundo da vida social. O autor, então, a partir de Max Weber, denomina esse esquema de conhecimento como "pensar habitual", ou seja, uma concepção relativamente natural do mundo.

${ }^{10}$ Todos os valores peculiares, instituições e sistemas de orientação e direção (tais como os estilos folclóricos, padrões morais, leis, hábitos, costumes, etiqueta, modismos) caracterizam - se não constituem - qualquer grupo social em um dado momento na sua história (Schutz, 2003). 
Quando há uma "crise" dessa forma de "pensar habitual", o padrão cultural de seu grupo não mais funciona como um sistema de testadas receitas à mão; isto revela que sua aplicabilidade está restrita a uma situação histórica específica (Schutz, 2003, p. 122).

Dessa forma, para o estrangeiro que se aproxima do grupo, há a necessidade de colocar em questão quase tudo que parece ser inquestionável para os seus membros. $\mathrm{O}$ padrão cultural não tem autoridade de um testado sistema de receitas, pois esse estrangeiro não compartilha da forte tradição histórica pela qual o grupo tem sido formado. Certamente,

Do ponto de vista do estrangeiro, também a cultura do grupo aproximado tem sua história peculiar, e esta história é até mesmo acessível a ele. Porém ela nunca se tornou uma parte integrante de sua biografia, como foi a história de seu grupo de origem. Somente as formas nas quais seus pais e avós viveram tornar-se-ão para cada pessoa elementos de sua própria forma de viver. (Schutz, 2003, p. 122).

Para o estrangeiro, o seu padrão cultural continua a ser o resultado de um ininterrupto desenvolvimento histórico e um elemento de sua biografia pessoal, ou seja, suas referências continuam sendo a de seu próprio grupo. Entretanto, quando o estrangeiro se aproxima do outro, está transformando-se de um despreocupado observador para um suposto membro do grupo aproximado. O padrão cultural do grupo aproximado, então, não é mais um assunto subjetivo de seu pensamento, mas um segmento do mundo que tem que ser dominado por ações. $\mathrm{O}$ padrão cultural do grupo apropriado para o estrangeiro não é um abrigo, mas um campo de aventuras, não uma coisa natural, mas um questionável tópico de investigação, não um instrumento para desvendar situações problemáticas, e sim, ele mesmo, uma situação problemática e difícil de dominar (Schutz, 2003).

Em suma, podemos dizer que o "estrangeiro" de Simmel e o de Schütz guardam certas especificidades. O viajante simmeliano não manifesta os dilemas apresentados pelo forasteiro de Schütz, enquanto este último, na tentativa de inserir-se no grupo, vivencia uma enorme tensão na assimilação e adaptação a um padrão cultural que lhe é estranho. Já em Simmel, há uma intrigante aceitação da condição do estrangeiro, ele 
passa a ser concebido como uma forma singular e positiva de participação (Tavares, 2001). ${ }^{11}$

Parece-nos que o mais interessante na abordagem dos autores é que ambos estão considerando o estranhamento e o conflito como uma condição para o estabelecimento e manutenção das relações sociais, ou como um elemento ativo no processo de fortalecimento da sociabilidade grupal. Cada qual constrói seu tipo ideal de estrangeiro, mas ambos querem entender como se dão as interações na sociedade.

No contexto de aproximação desse "estrangeiro" a um grupo social, está implícita a ideia de mobilidade, de um indivíduo que migra em direção a algum lugar, com um objetivo. A tentativa desse estrangeiro de compreender aspectos da cultura do outro, através das estruturas de significados do grupo, reflete, igualmente, a condição de que o antropólogo é também, por vezes, uma espécie de migrante. Nesse sentido, entendemos cultura como uma teia de significados construída pelos próprios homens (Geertz, 1982), sendo que a antropologia apresenta-se como uma ciência interpretativa que está em busca desses significados. Para que essa análise seja possível, o antropólogo deve ter em mente que o objeto da etnografia é uma hierarquia estratificada de estruturas significantes, de tal modo que as diversas situações e relações sociais devam ser percebidas e interpretadas por ele (Geertz, 1982). O antropólogo torna-se, com isso, um indivíduo que precisa romper vínculos originais e tentar reconstruir sua vida em outro lugar; nesse sentido, o migrante surge como um companheiro mítico, pois seu movimento reflete uma exigência que é feita a todos nós, já que precisamos romper os liames originais para nos afirmar enquanto agentes e sujeitos no campo do outro (Ferreira, 1999).

No transcorrer de sua peregrinação em busca de K., o narrador-viajante de Abreu (2002) observa constantemente um homem manco que o acompanha pelos lugares que cruza, sem nunca, de fato, estabelecerem qualquer diálogo.

\footnotetext{
${ }^{11}$ Para Tavares (2001, p. 87), [...] o estrangeiro itinerante de Simmel é apresentado a partir de uma valoração de sua condição. Seu olhar se reveste de um caráter de objetividade em relação aos demais, pois não se encontra mergulhado nos limites e incongruências daquela realidade social. [...] $\mathrm{O}$ estrangeiro de Schütz já não vivencia sua condição especial dessa forma. O conhecimento à mão por ele utilizado não configura garantia alguma para o estabelecimento de uma experiência do nós. Ao contrário, a possibilidade de construir uma relação de intimidade representa, para ele, um constante desafio e, em última instância, uma impossibilidade. Seu lugar é de confinamento. Sua condição, a de solidão.
} 
Um homem manco e velho, um tanto cansado e metido num sobretudo xadrez preto e branco, dirige-se lento às escadas para subir até onde estou. Não usa bengala ou muletas, o que me faz imaginar, talvez desejar, que tenha apenas um pé machucado ou algo assim, e portanto, mancar seja uma coisa passageira. Não um destino irremediável. (Abreu, 2002, p. 18).

O homem manco, nesse sentido, surge para lembrar a todo instante a condição de estrangeiro do narrador-viajante. O exílio pode ser entendido como um homem velho, manco e cansado, ou seja, a figura traz no corpo uma espécie de marca que o obriga a mancar, apresenta o aspecto da velhice para mostrar que se trata de uma prática antiga da humanidade e, ainda, perambula pela narrativa sem ter outra função a não ser lembrar constantemente o narrador-viajante de sua condição de exilado, de estrangeiro (Pires, 2007).

Nas interações sociais e na tentativa de ser aceito pelo grupo ${ }^{12}$, revelou-se uma série de impressões e tensões comuns entre o pesquisador e os sujeitos envolvidos na pesquisa. Dentro das especificidades que envolviam seus trânsitos e das motivações que norteavam suas práticas, o sentimento de estranheza era comum, pois experimentavam, assim como Meursault ${ }^{13}$, certa indiferença e descrença perante algumas situações da vida, pelo fato de estarem deslocados. A estranheza gerada pelo "estar longe" é definida por Said (2003, p. 46) em suas palavras sobre o exílio: "é uma fratura incurável entre um ser humano e um lugar natal, entre um eu e seu verdadeiro lar: sua tristeza essencial jamais pode ser superada. [...] As realizações do exílio são permanentemente minadas pela perda de algo deixado para trás para sempre”.

\section{Somos todos migrantes: os desafios colocados pela pesquisa etnográfica com migrantes quilombolas em Caxias do Sul}

Ao lançarmos um olhar para a historicidade da comunidade quilombola Arnesto Penna Carneiro percebemos as ações de expropriação de seu território original. Atualmente, a comunidade se distribui em uma área de em torno de 1,5 hectares ocupada por, aproximadamente, 56 habitantes, divididos em 13 residências. As difíceis

\footnotetext{
${ }^{12}$ Insularidade, nação, grupo. Encontramo-nos diante de territorialidades delimitadas a partir de um centro, cada uma delas configurando uma identidade, uma especificidade envolta pela exterioridade de suas fronteiras. Há sempre um "nós" e um "eles", um "dentro" e um "fora", um "familiar" e um "estranho" (Ortiz, 2000, p. 64).

${ }^{13}$ Personagem-narrador da obra $O$ estrangeiro, de Camus (2006).
} 
condições encontradas pelos quilombolas no âmbito da viabilidade de produção (não existem terras suficientes para esse fim), de mercado de trabalho (com poucas opções) e de remuneração (ganham pouco), fizeram com que muitos deles saíssem para "tentar a vida" em regiões distantes do quilombo, não sendo possível que permanecessem no território, próximo aos familiares. Os mais jovens eram os que mais sentiam a falta de oportunidades, sobretudo de aspirarem a uma "nova vida", longe do trabalho árduo na lavoura, que, "além de pagar pouco, judiava muito".

Nas pesquisas realizadas no quilombo, chamava atenção as categorias empregadas pelos quilombolas para se referirem ao "outro", aquele etnicamente diferente. Tais categorias eram criadas partindo de relações sociais marcadas, muitas vezes, por oposição, por contraste, no que diz respeito às identidades dos quilombolas; "os gringo", "os italiano", "os alemão" eram categorias de reconhecimento acionadas para referirem-se aos indivíduos de fora da comunidade.

Estranhando tais categorias e tentando compreender em que circunstâncias elas eram produzidas e manifestadas, Monteiro percebeu que a saída dos moradores do quilombo para outras regiões não era uma decisão casual, na realidade existia um significativo fluxo migratório para a cidade de Caxias do $\mathrm{Sul}^{14}$, RS, na qual eles transitavam. A partir dessa constatação, a realização de uma etnografia sobre o trânsito dos quilombolas resultou em dados interessantes para as categorias de reconhecimento "os gringos", “os italiano", “os alemão”, enquanto atribuições étnicas (do próprio grupo étnico ${ }^{15}$ ), e suas manifestações em uma cidade tipicamente de "italianos", contexto distinto da ruralidade na qual estava situado o quilombo, já que as experiências vividas pelos moradores que migravam eram seguidamente narradas pelos familiares que permaneciam na comunidade. Soubemos, em um primeiro momento, que se tratava, basicamente, de uma migração de jovens, que iam em busca de trabalho (Sayad, 1998) ${ }^{16}$

\footnotetext{
${ }^{14}$ É a cidade com maior número de habitantes da região, cerca de 435.564 (IBGE, 2010). É nela que se concentra o maior número de empresas do polo metal-mecânico gaúcho (Mocellin, 2011).

${ }^{15}$ Na perspectiva de Barth (2000, p. 32), os grupos étnicos são atributivos e identificadores, empregados pelos próprios atores, tendo como origem organizar as interações entre os indivíduos de determinados grupos; nesse sentido, "a atribuição de uma categoria é uma atribuição étnica quando classifica uma pessoa em termos de sua identidade básica, mais geral, determinada presumivelmente por sua origem e circunstâncias de conformação".

${ }^{16}$ Na perspectiva de Sayad (1998), é o trabalho que faz possível "nascer" o imigrante, qualquer imigração está vinculada à ideia de trabalho. A imigração, nesse sentido, segundo o autor, tem sua lógica no deslocamento direcionado dos locais mais pobres, com menos possibilidades de emprego, para os locais mais ricos, que acenam com esta oferta.
} 
e, após se estabilizarem em Caxias do Sul, articulavam a ida de irmãos, sobrinhos, primos e parentes que almejavam, assim como eles, "tentar a vida na cidade grande".

Ainda no final do ano de 2009, Monteiro conheceu a família de Paulo Cezar, o Cezinha, que residia em Caxias do Sul e que, com o advento das festividades de fim de ano, estava visitando com a esposa Andréia e as duas filhas Pâmela e Gabrieli os parentes no quilombo. Conversaram sobre a saída deles da comunidade, e o pesquisador mencionou que se interessava em entender o deslocamento para a cidade da Serra Gaúcha. Compreender a constituição das identidades dos migrantes por meio do estabelecimento de relações interétnicas entre grupos étnicos distintos, "negros" residentes em uma comunidade quilombola que migram e passam a residir em uma cidade de "italianos", tornou-se a questão central da pesquisa.

Já tínhamos em mente que estudar migrantes seria desafiador, especialmente por se tratar de indivíduos dispersos em uma cidade de porte médio, sabíamos apenas que moravam em Caxias do Sul, mas como encontrá-los? A comunidade quilombola em Santa Maria está estabelecida em um espaço razoavelmente pequeno, nesse sentido a pesquisa se tornava mais acessível em termos de convívio e comunicação. Dirigindo seu olhar para Caxias do Sul, Monteiro teria que exercitar o seu próprio desprendimento, deslocar-se para lá e se inserir nessa migração na medida em que quisesse compreendêla. Foi o que fez. O passo inicial foi justamente acionar os contatos estabelecidos anteriormente, a partir da família de Cezinha, para que a pesquisa começasse a ganhar viabilidade e contornos.

Em novembro de 2010, Barreiro conheceu Caxias do Sul pela primeira vez; a região da serra era um lugar do qual somente "tinha ouvido falar", sobretudo pelas histórias narradas pelos moradores do quilombo; nunca, de fato, tinha estado lá. O motivo que o levara foi um seminário sobre migrações ${ }^{17}$ que ocorreu na Universidade de Caxias do Sul (UCS), além da possibilidade de estabelecer as primeiras interações com ex-moradores do quilombo. Chegar a um lugar que nos é estranho é sempre um momento que nos gera certa apreensão; ainda que ele tivesse estabelecido contatos anteriores, a sensação de “será que vai dar certo?” era inevitável. Imaginem, então, o que representava para os informantes a entrada de um "estranho" em suas práticas

\footnotetext{
${ }^{17}$ Seminário sobre mobilidade humana e dinâmica migratória, ocorrido em 24 de novembro de 2010 e organizado pelo curso de licenciatura em Sociologia do Centro de Ciências Humanas da UCS e pelo Centro de Atendimento ao Migrante (CAM).
} 
cotidianas e em sua vida privada, um domínio íntimo, que não é aberto a qualquer "desconhecido".

Cezinha e Andréia, sua esposa, tinham uma rotina voltada para o trabalho, e não poderia ser diferente, estavam ali justamente por ele. Apesar da pouca disponibilidade de horários livres, conseguiu marcar uma entrevista. Quando Monteiro pediu a Cezinha um endereço onde pudessem se encontrar, ele fez questão de dizer que o buscaria no hotel no qual ele estava hospedado. Já dentro do carro, falou o que o levava até ele, mencionou os objetivos do trabalho, ponderou sobre sua formação profissional e contou sobre sua trajetória de pesquisa junto aos moradores do quilombo. Cezinha escutava, fazia alguns questionamentos, mas consentia, parecia estar disposto a ouvir o antropólogo, ao menos naquele dia.

Enquanto se dirigiam ao bairro em que a família residia, Cezinha mostrava o centro da cidade, indicava ruas, contava breves histórias de locais onde já havia trabalhado, comentava sobre as dificuldades do trânsito e da violência na cidade, apontava uma casa de shows a que costumava ir com a esposa, da mesma forma que dividia seu olhar para os belos carros que cruzavam pelo seu. Já no bairro onde residiam, chamado Planalto, disse que iria até o salão de beleza de Andréia, estabelecimento do qual sua esposa era proprietária juntamente com uma sócia que não estava naquela ocasião. O Salão de Beleza Novo Estilo estava situado em uma pequena galeria, que possuía também algumas lojas de presentes e uma lotérica. Ao chegarem, Andréia estava terminando o corte de cabelo de um garoto, em estilo "moicano", segundo ela, a tendência seguida pela freguesia jovem. Nossa conversa ocorreu no próprio salão de beleza, entre mulheres, esmaltes e cabelos esparramados pelo chão. Monteiro percebeu que eles não entendiam exatamente os motivos de sua ida até lá. Este então, explicou de maneira objetiva, dizendo que se interessava pela história da comunidade quilombola, pois era um território de tradições que estava localizado há mais de 100 anos naquele local, e que eles, apesar de não residirem mais lá, eram parte importante dessa história. Naquele momento, lembrou-se que havia levado uma cópia impressa do laudo sobre a comunidade. Foi então, a partir desse documento, que a explicação passou a fazer mais sentido à Cezinha e Andréia.

No folhar das páginas, ao examinar os mapas e visualizar as fotos, Monteiro percebeu que eles estavam dispostos a "dar um voto de confiança" para aquele "estranho" que se apresentava como um estudante de antropologia e que estava 
interessado em coisas que eles não sabiam muito bem "para que servia". Enquanto Andréia lixava as unhas de uma moça ${ }^{18}$, o casal contou como foi adaptar-se à "cidade grande", as dificuldades iniciais e as conquistas tão significativas, que jamais poderiam ter pensado em conseguir caso tivessem permanecido em Santa Maria, como, por exemplo, ter o próprio salão de beleza, o grande projeto da família, que havia dado certo até aquele momento. Identificaram e mapearam os familiares que estavam espalhados por diversos bairros da cidade. Foi um exercício de rememorar em meio a um sentimento de saudosismo combinado com emoção.

Ter oferecido o laudo sobre a comunidade naquela ocasião representou uma importante abertura dialógica, na medida em que "atestava" os objetivos de Monteiro e "garantia" que aquele "estranho" tinha "boas intenções". Na integração do estrangeiro com o grupo, a posição dentro do sistema de relevância do estrangeiro muda decisivamente, e isso significa que outro tipo de conhecimento é requerido para sua interpretação. Saltando da plateia para o palco e, então, para o discurso, o outrora observador torna-se um membro do elenco, entra como um protagonista dentro das relações sociais com seus coautores e participa, a partir daí, das ações em progresso (Schutz, 2003).

Conhecer os parentes do quilombo, saber quem eram seus pais, seus tios e primos, falar sobre determinados lugares que estavam guardados na memória, enfim, demonstrar conhecimento sobre a realidade da comunidade foi o ponto chave para que encaminhassem novos encontros e que a etnografia pudesse, enfim, tornar-se possível. Brindaram o final da entrevista com um café forte, servido em uma bandeja de plástico por Andréia. No retorno para o hotel, ao avistar um carro imponente, Cezinha disse: “Ah! Se eu tivesse um carro desses, venderia e construiria uma casa em Santa Maria". Apesar "das coisas estarem muito melhores hoje do que antes", ficou notório que, durante a entrevista, o sentimento de ambos se dava em uma esfera conflitiva. Mostravam-se, por um lado, felizes por estarem em uma "cidade de oportunidades" e terem, em virtude disso, concretizado projetos de vida, como o salão de beleza e o carro; mas, por outro, o olhar profundo dava a certeza de que a nostalgia na narrativa, acompanhada da tristeza do olhar profundo, se devia ao fato de que estavam longe dos

\footnotetext{
18 A jovem, que era estudante do curso de História da UCS, participou indiretamente da entrevista, lembrando lugares e nomes de pessoas importantes na cidade.
} 
familiares, "da nega veia", como diria Cezinha referindo-se à sua mãe que ainda residia no quilombo.

\section{“Aqui é só um oi e um tchau": aspectos da socialização em um bairro de migrantes}

O sentimento de estranheza se intensificou logo que Monteiro se mudou para a Serra Gaúcha. Alugar quarto em um apartamento com desconhecidos ${ }^{19}$, ambientar-me à cidade, pegar ônibus sem muita referência de onde descer, fazer contatos e situar os novos informantes da pesquisa constituíam-se em experiências que davam ao pesquisador a impressão de ser um estrangeiro.

Essa impressão, de indivíduo "de fora" ${ }^{20}$, começou a "cair por terra" quando Monteiro passou a realmente interagir com outras pessoas, igualmente "de fora". Certa vez, almoçando onde, costumeiramente, fazia suas refeições diárias, um senhor idoso, sentado na mesma mesa, puxando assunto, perguntou se Monteiro almoçava sempre ali, pois "a comida era sempre muito boa, quase caseira". Respondeu que não, que estava na cidade havia pouco tempo, estava a estudos e ainda se adaptando. Então, ele disse: "Meu filho, te acostuma que o que menos tem aqui é 'gringo puro', a maioria é 'de fora', da fronteira".

Em outra ocasião, ao perguntar para um taxista sobre o motivo de todos os táxis da cidade terem pequenas cabinas blindadas no entorno do assento do motorista, ele explicou-lhe que se tratava de uma lei que não permitia a circulação de veículos que não apresentassem esses espaços blindados. Monteiro questionou: mas por que em outras cidades essa lei não vigorava, já que a maioria dos carros circulava sem as tais cabinas? O taxista então afirmou: "Essa lei é municipal, só vale aqui, mas é que Caxias é um outro país, tudo aqui é diferente, tu ainda não percebeu isso?".

A ideia de que a cidade de Caxias do Sul era composta, na sua maioria, por estrangeiros, por indivíduos "de fora", foi outras vezes mencionada. Entretanto, essa constatação ficou mais evidente em termos empíricos quando o pesquisador conheceu o

\footnotetext{
${ }^{19}$ Foi um período em que o estranhamento inicial deu lugar, mais tarde, à amizade e à boa vontade dos rapazes que residiam comigo, os quais foram fundamentais para a minha adaptação ao estilo de vida da cidade.

${ }^{20}$ Essa categoria era recorrentemente utilizada, de um modo geral, para identificar os indivíduos nascidos e não-nascidos em Caxias do Sul.
} 
bairro onde residia a família de Cezinha. O lugar é chamado de "invasão do Planalto" ${ }^{21}$, localizado no bairro Planalto, não muito distante do centro de Caxias do Sul, um lugar constituído de moradias simples, de pessoas que, assim como Paulo Cezar e Andréia, foram para a serra em busca de trabalho: gaúchos, catarinenses, paranaenses, migrantes de diversas regiões do país, em especial do Sul, e alguns de outras regiões, como o Nordeste e Centro-Oeste.

A residência da família situa-se no morro e, para chegar até ela, foi necessário subir uma ladeira muito íngreme, por um caminho irregular de terra, duas listras estreitas de cimento serviam de passarela tanto para o trânsito de pessoas como de veículos. As casas, na maior parte, são de zinco e madeira, algumas de dois andares, umas pintadas, mas a maioria conserva a cor natural da madeira. $\mathrm{O}$ bairro tem em torno de dois hectares e meio e acolhe 120 famílias, sendo que os moradores costumam subdividi-lo em "invasão de baixo" (que se refere à parte de baixo do morro) e "invasão de cima" (parte alta do morro). Trata-se, enfim, de um bairro composto, na sua maior parte, por pessoas "de fora", migrantes.

A casa da família é constituída pelo salão de beleza de Andréia, na parte de baixo, e três cômodos (dois quartos e cozinha/sala) na parte superior. Andréia trocou o salão de beleza de endereço, pois "não estava fácil" arcar com as despesas do aluguel na galeria e, como a residência era da própria família, achou que seria mais vantajoso mudar-se, mesmo sabendo que a clientela poderia diminuir, pois a galeria estava situada em um ponto mais comercial. O salão passou a chamar-se Andréia Cabeleireira.

Em um domingo ensolarado de abril, a convite de Cezinha para um churrasco, Monteiro pode perceber aspectos da socialização entre os moradores do bairro. Naquele dia, havia uma intensa circulação de pessoas vinculadas a igrejas (evangélicas), que, de porta em porta, entregavam folhetos e falavam brevemente com os moradores; muitos desciam elegantemente a ladeira carregando a Bíblia embaixo do braço. Segundo Cezinha, lá prevaleciam as religiões evangélicas, "têm umas que nem o nome eu sei direito". As crianças subiam e desciam constantemente a ladeira, brincavam de pegapega, esconde-esconde; alguns jovens escutavam música ao celular; outros, em frente à casa, "tomando um sol", disseram que gostavam de morar ali, pois era um lugar

\footnotetext{
${ }^{21}$ Trata-se de uma parte do bairro Planalto que foi invadida há mais de 10 anos. Era inicialmente uma propriedade particular situada em um morro e em seus arredores. Atualmente, os moradores dessa invasão estão envolvidos em um processo jurídico com a prefeitura e o proprietário, visando expropriar e realocar essas famílias.
} 
tranquilo, a maior reclamação era dos garotos que não jogavam futebol ali, porque o espaço não permitia, tinham que descer o morro para jogar em um campinho que existia na parte de baixo.

A rotina dos moradores do bairro é voltada para o trabalho. Segundo Andréia, nos dias de semana, "é cada um na sua, só um 'oi' e um 'tchau”; no entanto, o domingo é o dia em que há maior movimentação, muitos preparam as churrasqueiras, geralmente de tonéis de lata cortados, pessoas, aparentemente, de outros lugares sobem com espetos e sacos de carvão. "Domingo é assim, uma festa...", esclareceu Andréia. Gente na frente das casas, janelas abertas, mulheres limpando tapetes, homens tomando chimarrão, além das muitas sonoridades (música sertaneja, gaúcha e $p o p$ ), que não deixavam dúvidas de que o domingo no bairro Planalto era mesmo dia de festa.

\section{Negociando horários e experiências: a pesquisa etnográfica oportunizando encontros}

Quando passou a procurar os outros ex-moradores do quilombo, logo diziam que "só estariam em casa à noite". Com isso, Monteiro precisava organizar as idas a campo de forma que não atrapalhasse a rotina dos informantes e, também, que não fossem entrevistas demasiado extensas, já que, em certas ocasiões, alguns se mostravam cansados. A maioria das entrevistas aconteceu na parte da noite, após às $19 \mathrm{~h} 30 \mathrm{~min}^{22}$, no salão de beleza de Andréia, por escolha dos próprios informantes e por ser um espaço mais amplo. Bocejos indicavam quando a entrevista deveria ser encerrada e o gravador desligado.

No período da pesquisa ${ }^{23}$, residiam em Caxias do Sul 13 ex-moradores ${ }^{24}$ do quilombo. Desse total, seis se dispuseram a participar da pesquisa ${ }^{25}$; alguns desses informantes possuíam uma rede extensa de parentesco, esposas, filhos, sogras, primos

\footnotetext{
${ }^{22}$ Horário em que a maioria dos informantes já havia retornado do trabalho, salvo os dias em que ficavam até mais tarde, fazendo o "cerão", ou seja, trata-se de uma categoria utilizada para se referirem ao fato de realizarem hora extra no trabalho. Mencionaram que o "cerão" funciona como forma de adquirir uma renda extra no fim do mês, e alguns me contaram que, em determinados meses, chegaram a "dobrar" o valor do salário fixo.

${ }^{23}$ Residi em Caxias do Sul nos meses de abril e maio de 2011, posteriormente fiz incursões mensais ao campo até janeiro de 2012, especialmente, nos feriados e finais de semana.

${ }^{24}$ Estes são descendentes diretos dos Penna e representam a terceira geração, que ainda continua vivendo na comunidade.

${ }^{25}$ Todos foram convidados a participar, pessoalmente ou por telefone, mas alguns não demonstraram interesse. Timidez e compromissos pessoais foram os principais motivos alegados.
} 
etc., que também migraram para Caxias do Sul. Com isso, os informantes foram de 10 a 12 pessoas $^{26}$. As entrevistas não foram baseadas em um roteiro preestabelecido ${ }^{27}$. Monteiro realizava as perguntas abertamente, que incluíam dados sobre a biografia individual $^{28}$ do migrante na cidade de origem e na cidade receptora. Cada entrevista durou em torno de uma hora e meia. Por tratar-se de uma pesquisa de caráter qualitativo, o antropólogo não levou em consideração o problema da representatividade. Cumpre destacar que, na maior parte do tempo, o pesquisador dedicou-se à observação de uma família de migrantes (Cezinha e Andréia), embora tivesse feito entrevistas com os outros informantes.

Os ex-moradores do quilombo distribuem-se em bairros distantes, com exceção de Luiz Antônio, o irmão mais velho de Cezinha, conhecido popularmente como "Chique", que estava na cidade havia poucos meses, residia quase em frente à casa do irmão e morava com a esposa e os cinco filhos. Essa dispersão dos informantes impedia de acompanhar o cotidiano desses sujeitos, tanto em razão da distância dos bairros, como pelos vínculos e interações criados mais com uns do que com outros. Uma das direções que Monteiro encontrou para viabilizar a realização das entrevistas, tendo contado com a fundamental contribuição de Cezinha, foi agendar antecipadamente, na casa do casal, os encontros com "os parentes" de outras regiões da cidade. Como muitos não tinham como se deslocar à noite até o bairro Planalto, Cezinha encarregava-se de buscá-los.

Somados à rotina exaustiva do dia de trabalho, os informantes tinham ainda seus compromissos religiosos em três noites por semana, a ida ao culto da igreja "Deus é Amor" ${ }^{29}$ era imprescindível. Ressaltamos, com isso, que eram poucos os dias da

\footnotetext{
${ }^{26}$ Em algumas entrevistas, faziam-se presentes os esposos(as), que, de alguma forma ou de outra, participavam das conversas, mas não queriam ser incluídos na pesquisa. Destacamos, ainda, que Monteiro não utilizou as entrevistas de todos os informantes, pois se deteve na história de vida de alguns deles.

${ }^{27}$ Tentei esquematizar um roteiro prévio, mas, quando fui aplicá-lo, percebi que os informantes sentiamse mais confortáveis para falar, sem que eu fizesse perguntas prontas e diretas (em tom mais formal). Geralmente, iniciava as entrevistas falando sobre os acontecimentos da semana, sobre como havia sido o dia no trabalho e o clima em Caxias do Sul (em especial nos dias mais frios).

${ }^{28}$ Quando se fala de história de vida, de biografia, pressupõe-se uma "unidade do eu", mas, na realidade, trata-se de uma formidável abstração. Essa ilusão compreende a ideia de uma identidade coerente; de um todo com projetos e intenções, de uma trajetória de acontecimentos sucessivos. A ordem cronológica com que se organizam biografias imprime à vida uma lógica retrospectiva e prospectiva, preocupada em dar sentido à existência. O próprio nome, a individualidade biológica e a assinatura asseguram a constância e alimentam a ilusão de unidade, quando, na verdade, o eu é fracionado e múltiplo (Alberti, 2000).

${ }^{29}$ No site de pesquisa Wikipédia, a foto que ilustra a página com informações da "Deus é Amor" é a do prédio que está situado na comunidade quilombola Arnesto Penna Carneiro. Segundo o site, a Igreja
} 
semana que eles tinham disponíveis para receber o pesquisador, em certas ocasiões as entrevistas se estenderam próximo à meia-noite. De qualquer forma, os informantes que desejaram participar da pesquisa mostraram-se interessados em compartilhar suas trajetórias. Cezinha fazia questão de apresentar Monteiro como "antropólogo da Universidade de Santa Maria", tanto no bairro, como no passeio que fizeram para conhecer os pontos turísticos de Caxias do Sul, como os pavilhões da Festa da Uva ${ }^{30}$ e o Monumento Nacional ao Migrante ${ }^{31}$; ele se referia dessa maneira: "um rapaz que está fazendo uma pesquisa sobre nossa história".

A possibilidade de realização das entrevistas passava pela "legitimação" de Cezinha e Andréia. Certa vez, ela ligou dizendo que havia um primo de Cezinha que não gostaria de ser entrevistado, "não queria seu nome no trabalho", que ele era "um bobo por não querer ajudar na pesquisa". Ela aconselhou Monteiro a não ir atrás do primo, pois ele "tinha esse jeito mesmo". A articulação das entrevistas era realizada pelo casal, que fazia questão de "colocar um cartão no celular para ligar para os parentes", explicando quais eram objetivos do trabalho, ou seja, eles estavam dispostos a inserir o pesquisador na rede de relações familiares. Isso foi fundamental para que a realização do trabalho fosse possível. Além disso, os momentos de realização das entrevistas eram ocasiões em que os parentes poderiam, mesmo que breve e esporadicamente, reunir$\mathrm{se}^{32}$

A intenção de compreender como esses sujeitos organizavam suas vidas cotidianamente encontrou empecilhos porque, para o pesquisador, o cotidiano dos

Pentecostal "Deus é Amor" (IPDA) é uma denominação evangélica brasileira originária da segunda onda do Pentecostalismo. Foi fundada em 1962, pelo missionário David Martins Miranda, com sede na cidade de São Paulo, Brasil. A sua membresia foi estimada em 774.830, conforme censo feito pelo IBGE (2000). Atualmente, conta com mais de 17.584 igrejas espalhadas pelo Brasil e mais 136 países, sendo a quinta maior igreja em número de membros do ramo pentecostal no Brasil, ficando atrás da Assembleia de Deus, Congregação Cristã no Brasil, Igreja Universal do Reino de Deus e Igreja do Evangelho Quadrangular e em nono lugar entre as igrejas protestantes brasileiras.

${ }^{30}$ Trata-se de um grande espaço onde é realizada a Festa da Uva. O local é aberto a visitações e recebe muitos turistas nos fins de semana, onde, principalmente, os caxienses aproveitam a estrutura do local para praticarem atividades de lazer. Naquela ocasião, observei muitas famílias circulando e fotografando o local.

31 O Monumento Nacional ao Imigrante, com estátuas de bronze de quatro metros e meio de altura concebidas pelo escultor Antônio Caringi, foi construído com basalto da região pelo arquiteto Sílvio Targo. Este mesmo escultor construiu, em Porto Alegre, a Estátua do Laçador, símbolo do gaúcho e também impregnado de significações étnicas e distintivas (Santos, 2004).

${ }^{32}$ Geralmente, após as entrevistas, jantávamos na casa de Cezinha e Andréia. Eram momentos de descontração, com as crianças brincando pela casa, em que eram contadas histórias engraçadas, piadas e fofocas do trabalho, enfim, um momento de encontro dos "parentes" que, apesar de residirem na mesma cidade, pouco ou raramente se reuniam. Acredito que minha pesquisa tenha sido uma facilitadora desses encontros. 
pesquisados talvez seja o mais difícil de ser analisado. Primeiro, porque é rompido pela própria presença do pesquisador, que fez vir à sala a dona de casa, que fez interromper a sesta do marido, que fez com que trouxesse o café na bandeja de plástico e que se calassem as crianças, além dos gravadores e cadernos de campo. Há ainda a verbalização necessária, suscitada ou incitada pelo pesquisador, mesmo quando ele pergunta sobre o mais genérico, quando, com mais delicadeza, sugere o interesse em tal ou qual assunto (Duarte, 1986).

Essas pessoas falam, falam entre si, falam sozinhas, sistematizam frequentemente com intensa perspicácia áreas enormes e densas de suas vidas, atualizam discursos diversos segundo suas próprias e diferenciadas relevâncias e planos. Podem até mesmo - como sei ter ocorrido, apesar daquele meu generalizador temor - falar coisas tais como não seria próprio que falassem com a maior parte dos seus, fazer confidências, explorar com um 'estranho' dimensões também um tanto 'estranhas' de suas vidas. (Duarte, 1986, p. 17, grifo nosso).

No contexto da pesquisa, esse "rompimento do cotidiano", de que fala Duarte, dava-se no momento em que as pessoas tinham que sair de suas casas para contar a um "estranho" certas dimensões de sua vida. Contudo, Monteiro sempre que possível buscou interagir e observar aspectos de suas vidas cotidianas nos fins de semana, quando alguns se mostravam dispostos a recebê-lo, em especial a família de Cezinha e Chique.

Nos trabalhos de campo realizados no quilombo, passavam as tardes embaixo de um pé de laranjeira, ouvindo as histórias que eram contadas no sossego do ambiente rural. O "tempo" das pessoas era outro. Em Caxias do Sul, no ambiente urbano, todos tinham uma ideia de tempo mais complexa, que deveria ser ocupada da melhor maneira possível $^{33}$. A decisão em permanecer temporariamente na cidade foi, justamente, para que Monteiro se enquadrasse, da melhor forma possível, no "tempo" deles. Tinha a preocupação constante em não alterar por demais suas rotinas, mesmo sabendo que sua presença já ocasionaria uma alteração, um rompimento ${ }^{34}$.

\footnotetext{
${ }^{33}$ Além de uma reorganização temporal, a mudança acarreta também uma modificação da própria concepção de tempo, pois os migrantes concebem de forma diferente o "tempo" no meio rural e na cidade (Menezes, 1976).

34 “Assim, eu não tardava a verificar que o etnólogo, apenas por sua presença, modifica, por vezes até perturba o jogo dos equilíbrios ou dos desequilíbrios do corpo social em que ele se imiscuiu. Qualquer que seja seu comportamento, não é senhor das interpretações que suscita: conscientemente ou não, tornase uma prenda do jogo entre as facções existentes e, quando gostaria de ser o sujeito observador, corre o risco de ser ele mesmo um objeto manipulado" (Wachtel, 1996, p. 46).
} 
Sua presença em campo estava, inicialmente, associada às "questões das terras". Como havia feito parte da equipe que escreveu o laudo sobre a comunidade, eles esperavam do antropólogo uma resposta que tivesse referência aos dos assuntos do processo de titulação das terras. Seguidamente, era questionado sobre o que era esse "negócio de quilombo". Percebia que havia certo desgaste, desconfiança e desconhecimento quando o assunto permeava essa esfera. Explicava sobre seu trabalho e sobre o laudo antropológico, os propósitos distintos de cada um, ainda que enfocassem o mesmo grupo. Nessas conversas, percebemos que havia entre eles uma circulação que não era somente de indivíduos ou de informações a respeito de acontecimentos ocorridos no quilombo e em Santa Maria, as quais tanto chegavam até Caxias do Sul e como faziam o sentido inverso, mas também de assuntos rotineiros ${ }^{35}$.

Certo dia, em uma conversa com Chique, ele se queixava de que Santa Maria não oferecia oportunidades de trabalho, além daquelas do ramo comercial e de serviços, que "não davam conta e pagava pouco"; reclamava que não havia, na cidade, indústrias como em Caxias; culpava as lideranças e políticos locais. Mas ele "estava sabendo" que uma indústria de carros blindados da Alemanha ${ }^{36}$ estava prestes a ser inaugurada na cidade, "pode ser que agora as coisas comecem a melhorar por lá", afirmou. Falava com entusiasmo da informação que tinha "ficado sabendo" da terra natal, ressaltou que só não havia ficado por lá pois "aqui existiam muito mais oportunidades, mais empresas e indústrias".

Apesar da distância, as pessoas estavam sempre bem informadas sobre os acontecimentos que envolviam Santa Maria, o episódio referente às terras era prova disso, tanto os moradores do quilombo como os que residiam em Caxias do Sul compartilhavam um sentimento comum de expectativa e desconfiança sobre terem suas terras tituladas. Compreendemos que há, nessa mobilidade de sujeitos, o deslocamento não somente físico, como também de ideias, experiências, saberes, enfim, vínculos que não são rompidos pela distância espacial e temporal. O quilombo permanecia como uma

\footnotetext{
${ }^{35}$ Os canais comunicativos entre migrantes e seus parentes nos locais de origem podem cobrir "centenas de quilômetros" em uma "estrutura social de referência" que "não é a local, nem a visível". O procedimento de acompanhar alguns migrantes possibilita a identificação de diversos canais de transmissão da informação e da tradição, que não são estritamente rurais e locais (Ratts, 2007, p. 266).

${ }^{36}$ Matéria veiculada no jornal Diário de Santa Maria de 13 de abril de 2011 diz que: a fábrica alemã de carros blindados Kraus-Maffei Wegmann (KMW) confirmou ontem que pretende fabricar, no futuro, dois novos carros blindados de transportes de tropas e um sistema de pontes móveis em sua primeira unidade no Brasil, que será aberta em Santa Maria. Antes de iniciar a fabricação, começará a operar, no início de 2012, na cidade, uma unidade de manutenção dos 220 tanques de guerra Leopard 1A5 e um centro de desenvolvimento de novos veículos blindados que a empresa pretende vender ao Exército Brasileiro.
} 
referência para mencionarem as condições de vida em que se encontravam em Caxias do Sul. A melhoria de vida em certos aspectos, ou as dificuldades enfrentadas em outros, tinham o quilombo e Caxias do Sul como realidades colocadas em comparação.

A migração desses sujeitos representava uma espécie de balizador das suas experiências, um antes e um depois, "lá fora era estranho, na cidade é comum", "no quilombo não existia, em Caxias é normal", evidenciando, de certa maneira, que aquele território de origem se faz presente na vida cotidiana desses migrantes ${ }^{37}$. Nesse sentido, Monteiro percebia que cumpria uma função de "informante" sobre assuntos que se referiam a Santa Maria, "aquele que traz boas novas, ou nem tão boas novas assim". Era constantemente questionado sobre as condições das estradas, de clima, sobre a vida política da cidade e, principalmente, sobre os parentes do quilombo, ao mesmo tempo que era levado para conhecer lugares turísticos, orientado a pegar determinadas linhas de ônibus ou ir ao supermercado nos melhores horários. Era informante e igualmente informado. Um pesquisador querendo compreender a migração, mas, ao mesmo tempo, um migrante.

Essa impressão que despertava de ser uma espécie de "antropólogo-nativo", um pesquisador e também um pesquisado, é abordada por Silva (2000) quando, na obra $O$ antropólogo e sua magia, o autor discute as relações de poder e de conhecimento existentes em uma pesquisa antropológica, mais especificamente referindo-se à escrita de um texto etnográfico, produto final de um esforço empírico e intelectual. $\mathrm{O}$ autor critica textos assépticos, na chamada "narrativa etnográfica impessoal e genérica" (Silva, 2000, p. 124), a qual é esvaziada dos aspectos subjetivos, em uma linguagem condizente com as exigências da racionalidade científica. Para o autor, mais importante do que essa linguagem estritamente científica são as agruras, dificuldades, facilidades, sentimentos despertados e afetividades do campo, incorporadas no corpo do texto. Elas revelam uma série de questões que dizem respeito aos "nativos" pesquisados, às suas vivências, aos seus relacionamentos e experiências empíricas, que passariam

\footnotetext{
${ }^{37}$ A experiência de fronteira é sentida como um acontecimento (considerado o nível da experiência nova e singular que no próprio impacto ainda não está codificado e, portanto requer uma pressa à sua assimilação, pois requer uma interpretação), narrado e interpretado pela saída de um lugar de origem para a chegada a um novo lugar. Esse movimento ganha de partida possibilidades de sentidos polifônicos, pois, o lugar físico compreende um lugar psíquico e especulativo, contemplados nos processos imaginários que levam a projeções e introjeções da condição humana. Projeções, daquilo que se pretende com o gesto e introjeções daquilo que fica como resultado, como imagem na realização do deslocamento com seus ganhos e perdas, em que podemos considerar um efeito balança - ali os valores são cotados (Xavier, 2007, p. 140).
} 
despercebidas e empobreceriam o texto etnográfico pelo rigor empregado em objetiválos. Trata-se, de certa forma, também de uma possibilidade de partilha em níveis diversos (Fabian, 2006; Comaroff, 1992; Marcus, 1991).

Convivendo com os migrantes e, por que não dizer, vivendo como um, Monteiro mergulhou nas tramas e enredos sociais cotidianos da família de Cezinha, procurando trazer aspectos conjeturais e subjetivos envolvidos na migração dessa família para Caxias do Sul a partir de um olhar antropológico ${ }^{38}$ voltado para aspectos da trajetória e biografia. Mas, como ressalta Fonseca (1999), o pesquisador, ao utilizar-se do método etnográfico, deve sempre situar os sujeitos de sua pesquisa em um contexto histórico e social, não pode torná-los a-históricos e atemporais; sem a contextualização, o "qualitativo" não traz acréscimos significativos à reflexão acadêmica. O aspecto social da análise pode combater uma tendência oriunda do individualismo metodológico, de isolamento do sujeito da pesquisa de seu contexto. Assim, é importante atentarmos para dois aspectos envolvidos no fazer etnográfico: que nossos modelos de compreensão são criações abstratas que nos permitem fazer sentido do "outro", entretanto, são simplificações grosseiras da realidade; e, ainda, que nunca devemos prever de antemão que nossos modelos sejam "a chave da compreensão" ou sequer tenham relevância quando lidamos com casos específicos; eles devem ser trabalhados como uma hipótese, ao lado das outras hipóteses. Servem para oferecer uma alternativa, para abrir o leque de interpretações possíveis, não para fechar o assunto ou criar novas fórmulas dogmáticas (Fonseca, 1999).

Compartilhamos com Elias (1995) a ideia de que, para se compreender alguém, é preciso conhecer os anseios primordiais que este deseja satisfazer. A vida, diz ele, faz sentido ou não para as pessoas, dependendo da medida em que elas conseguem realizar tais aspirações. Mas os anseios não estão definidos antes de todas as experiências. Desde os primeiros anos de vida, os desejos vão sendo definidos, gradualmente, ao longo dos anos, na forma determinada pelo curso da vida; algumas vezes, porém, isso ocorre de repente, associado a uma experiência especialmente grave. É comum não se ter consciência do papel dominante e determinante desses desejos, e nem sempre cabe à pessoa decidir se seus desejos serão satisfeitos, ou até que ponto o serão, já que eles sempre estão dirigidos para outros, para o meio social. Quase todos têm desejos claros,

\footnotetext{
38 “A vocação essencial da antropologia não é responder às nossas questões mais profundas, mas colocar à nossa disposição as respostas que outros deram [...] e assim incluí-las no registro de consultas sobre o que o homem falou" (Geertz, 1982, p. 40-41).
} 
passíveis de ser satisfeitos; quase todos têm alguns desejos mais profundos, impossíveis de ser satisfeitos, pelo menos no presente estágio de conhecimento.

A (re)construção de trajetórias por meio da história de vida de uma família migrante permitiu entender os processos sociais dotados de sentido, cuja significação se tornou possível a partir de uma compreensão diacrônica da realidade desses sujeitos. Fixar o olhar na "mudança" ao nível dos indivíduos nos permitiu acompanhar particularidades e pluralidades envolvidas no processo de busca de novas perspectivas de vida e ascensão social dessa família e de alguns "parentes" em um novo contexto. Se entendermos a "ascensão" como o resultado da "busca", deixaremos de ver os migrantes apenas como um produto, mas como produtos desse processo social.

\title{
Método e escrita etnográfica: encontros, contornos e estratégias
}

\author{
Encontros...
}

Compreendemos que a grande riqueza da pesquisa etnográfica está no fato de ela ser um método científico que possibilita o encontro entre subjetividades, entre o "eupesquisador" e o "outro-pesquisado", ainda que este "eu" possa tornar-se um pesquisado, e o "outro", um pesquisador; são papéis que se alteram, que se redimensionam a cada nova experiência vivida concreta e sentimentalmente em campo (Silva; Reis; Silva, 1994).

A tendência do antropólogo em sempre recorrer à etnografia marca fortemente sua identidade científica, o fazer etnográfico é o que define o seu ethos de pesquisador. O fato de os informantes, seguidamente, vincularem Monteiro ao sujeito que sabia sobre as "questões das terras" nos mostraram que a etnografia possui muitos contornos, sobretudo políticos. A etnografia utilizada no contexto de elaboração de laudos antropológicos não é mais pautada naqueles moldes clássicos e românticos do século XIX; o lugar que o antropólogo ocupa na sociedade hoje envolve uma imensa responsabilidade social (Leite, 2004).

Certa vez, em uma entrevista com um jovem em Caxias, este questionou Monteiro sobre os projetos e as políticas públicas que haviam sido implementados na comunidade Arnesto Penna Carneiro nos últimos anos. Queixava-se que nada acontecia em termos práticos, que os moradores continuavam em condições difíceis de 
sobrevivência e que esse "negócio de quilombolas era para estampar capa de jornais com pobreza". A fala do jovem pode ser entendida no sentido de uma estratégia de "proteção" contra aqueles que retratam a comunidade como um lugar de pobreza, de gente pobre. Eles não aceitavam ser vistos dessa forma, por isso não estavam dispostos a falar sobre suas vidas, como aconteceu com esse jovem e outros que foram convidados a participar da pesquisa.

Ao tratar sobre a publicação de resultados de uma pesquisa em Ciências Sociais e levando em consideração a rejeição do jovem em falar sobre sua vida, Becker (1977) alerta que o pesquisador, frequentemente, vai se deparar com limitações originadas de problemas éticos. Essas limitações podem ser tanto considerações que venham a ser prejudiciais ao grupo quando da publicação dos resultados, quanto questões que consideramos ser nocivas, mas não necessariamente o são. De qualquer maneira, o pesquisador estará obrigado a pensar se é relevante a publicação desses dados ou não. Para esse dilema, o autor conclui que não há uma receita pronta e fácil, de modo a resolvê-lo. Essas decisões são de ordem individual, quando o pesquisador, em negociação travada entre a sua moral e a do grupo, luta por manter condições de relatório o mais livre possível.

Tais encontros acabam tornando-se, muitas vezes, relações de cumplicidade entre o pesquisador e os sujeitos envolvidos na pesquisa; criam-se vínculos de confiabilidade, de amizade, da mesma forma que as expectativas, quando não correspondidas, podem gerar situações de desconfiança e rejeição. Por isso, a etnografia pode assumir muitos contornos.

\section{Contornos...}

Ter participado da equipe interdisciplinar que elaborou o laudo da comunidade gerou a Monteiro uma série de conflitos, refletidos tanto no trabalho de campo realizado na comunidade como em Caxias do Sul, conflitos estes que foram igualmente refletidos no ato de escrita do texto antropológico. Aquelas respostas não tão bem esclarecidas, as expectativas criadas quando discutiam sobre a possibilidade de eles terem suas terras de volta foram reticências e interrogações constantes.

$\mathrm{O}$ ato de escrever é a configuração final do trabalho de campo, o processo de textualização, ou seja, quando se trazem os fatos observados - vistos ou ouvidos - para 
o plano do discurso. Essa tarefa é bastante complexa e exige o despojo de alguns hábitos de escrever e perceber a escrita também como uma formatação do vivido para a linguagem científica (Clifford, 1998). É necessário adequar a escrita a uma atitude antropológica que leve em consideração a delicada técnica de colocar no texto nossas observações do "outro". Acima de tudo, trata-se de um trabalho "moral, político e epistemologicamente delicado" (Oliveira, 2000, p. 26).

Entendemos que a elaboração de um texto etnográfico tem de partir da própria reflexão de obtenção dos dados. Nele devem constar as intersubjetividades que estão presentes no campo. A escrita é o meio pelo qual temos a possibilidade de fazer a "costura" entre dado e teoria. Ela assume um caráter de legitimidade na medida em que demonstra, por meio da fala dos informantes, que o antropólogo realmente "esteve lá". Isso, sobretudo, torna evidente a responsabilidade que um texto assume, na medida em que, além de trazer a sua própria voz, traz a voz do "nativo" para dentro de si, esta não podendo ficar obscurecida ou resguardada pelas falas dos informantes. Esse é o caráter polifônico da escrita etnográfica, ou seja, as múltiplas vozes dispersas ou ordenadas pelo discurso científico que compõem o texto antropológico.

James Clifford (2002) destaca que a escrita etnográfica, ao tentar fazer uma tradução da experiência para a forma textual, encena uma estratégia de autoridade. $\mathrm{O}$ pesquisador, utilizando-se de recursos como pronomes em primeira pessoa, por exemplo, quer demonstrar a legitimidade que ele tem para falar do assunto. A autoridade sempre existirá, seja no processo experimental, seja no interpretativo, dialógico ou polifônico. Na concepção de Cardoso de Oliveira (2000), os atos de escrever e pensar são solidários entre si e formam um mesmo ato cognitivo; assim, logo que as observações estão devidamente organizadas, inicia-se o processo de textualização, ao mesmo tempo que se inicia o processo de produção de conhecimento.

Ao questionar sobre a própria produção de conhecimento e para quem, afinal, estamos produzindo-o, mesmo não sendo fácil esclarecer tais proposições, entendemos que o papel social que o antropólogo assume, no que diz respeito à produção de laudos antropológicos, a partir do momento em que é colocado no centro do debate sobre a conceituação de quilombo com a finalidade de garantir o preceito constitucional, é um importante desafio, que deve estar relacionado às nossas práticas científicas. Sobretudo, na utilização do método etnográfico em contextos de pesquisas com distintas finalidades, tendo em vista, principalmente, a disseminação das reformas 
constitucionais e implementação de políticas de reconhecimento da diversidade sociocultural nas últimas décadas, especialmente nos países latino-americanos, onde novos conceitos, saberes e práticas foram e estão sendo incorporados pelos estados nacionais, visando à garantia de direitos às populações étnico-raciais que, historicamente, estiveram em estado de vulnerabilidade social.

Ao entrar em campo, o pesquisador terá de lidar com inúmeras situações, que exigirão dele um posicionamento, uma maneira de se colocar no assunto, buscando não alterar demasiadamente o ordenamento e constituição social do grupo. Terá que estar atento aos acontecimentos cotidianos, para, a partir disso, elaborar estratégias de interação social.

\section{Estratégias...}

A etnografia é, como já mencionamos, além de um método que norteia o fazer antropológico, um instrumento que possibilita a interação entre sujeito e objeto, ou seja, um processo marcado pela intersubjetividade própria da interação social. Assim, quando um indivíduo se apresenta diante dos outros, como, por exemplo, um pesquisador ao entrar em campo, seu desempenho tenderá a incorporar e exemplificar os valores oficialmente reconhecidos pela sociedade e até mais do que o comportamento do indivíduo como um todo. Se entendermos a vida social na perspectiva de Goffman (1992), ou seja, como uma representação teatral, podemos dizer que interpretamos, para cada grupo, uma expressão a um padrão ideal de representação, de acordo com atitudes que façam com que possamos ser bem aceitos em grupos específicos.

Esse "ser bem aceito" por um grupo passa pela necessidade de reconhecer certas regras de convívio social, daquilo que é compartilhado e que faz sentido para os indivíduos, compreender o que faz com que se sintam motivados a falar, a opinar e a discutir sobre determinados assuntos, ou silenciar-se e abster-se frente a outros. Na sua condição de universitário do sexo masculino pesquisando migrantes, existiam certas facilidades no trato das relações sociais, em especial com os homens; todavia, também se colocavam algumas barreiras a serem ultrapassadas, para que fosse possível a compreensão de certas estruturas de significados postas naquele contexto. Era imprescindível para isso um "jogo de cintura”, para estabelecer um diálogo mais próximo. Acreditamos que uma estratégia que tenha proporcionado uma maior abertura 
no campo das interações tenha sido a entrada no universo feminino, por meio da vontade que Barreiro manifestou em ter meus cabelos cortados por Andréia em seu salão de beleza.

Entre o corte objetivo da tesoura e o deslizar da navalha bem afiada, Andréia narrou sua trajetória de vida, da dureza de ser mulher negra em Caxias, da criação das duas filhas, do zelar pela casa, do atendimento no salão e da espera de mais um filho. Falou da saudade que sentia da mãe, das dificuldades da vida em Santa Maria e do esforço depositado em si mesma para chegar até onde chegou. Via-se como uma vencedora, daquelas que não desistem. Apesar do jeito meio quieto, era uma jovem de percepção muito aguçada, atenta e de opinião formada. Confiar a ela que cortasse seu cabelo deu, sem dúvidas, um novo "visual" à pesquisa. Ao término do corte, ao olhar para o grande espelho, ainda sentado na cadeira giratória, Barreiro viu que a imagem do estranhamento foi sendo obscurecida pela imagem da confiabilidade e do respeito.

Toda e qualquer relação intersubjetiva, como essa descrita, é uma relação dialógica. No que diz respeito ao método etnográfico, essa relação guarda pelo menos uma grande superioridade sobre os procedimentos tradicionais de pesquisa. Faz com que os horizontes se abram um ao outro, de maneira a transformar tal confronto em um verdadeiro "encontro etnográfico". Cria-se um espaço semântico partilhado por ambos os interlocutores, graças ao qual pode ocorrer a "fusão de horizontes", desde que o pesquisador tenha habilidade de ouvir o nativo e por ele ser igualmente ouvido, estabelecendo-se um diálogo entre "iguais", sem receio de estar, assim, contaminando o discurso do nativo com elementos de seu próprio discurso. $\mathrm{O}$ ouvir ganha em qualidade e altera uma relação de mão única em uma de mão dupla, portanto uma verdadeira interação (Oliveira, 2000).

Quando foram abertas as portas do universo particular dessa família migrante, quando sentou no sofá da sala pela primeira vez, secou a louça acumulada no escorredor e ajudou a preparar o churrasco de domingo, de fato, esse diálogo entre "iguais" foi sendo possível. Anteriormente, Barreiro tinha realizado somente as entrevistas no salão de beleza, com um caráter demasiado formal; agora, já falavam do vizinho da frente, da água que costumava faltar e dos planos de reformar alguns cômodos da casa. Parecia que as falas se davam com mais naturalidade e sem aquela inibição das primeiras vezes.

Através da obra Corpo e alma: notas etnográficas de um aprendiz de Boxe, de Wacquant (2002), podemos analisar como o autor conseguiu adentrar, lenta e 
gradativamente, em um universo de boxeadores negros, a academia de boxe de Woodlawn, chamada de Gym Boy and Girl Club of Woodlawn, na periferia de Chicago, nos Estados Unidos. Inicialmente, ele tinha o objetivo de servir-se da academia como uma "janela" para o gueto, queria compreender as estratégias sociais dos jovens do bairro. A metodologia adotada por Wacquant é uma inversão da tradicional fórmula “observação participante", tornando o método uma "participação observante". Ele passa a participar da academia de boxe como um aprendiz, refletindo em uma mudança de seu status e seu papel nas relações com os outros boxeadores.

Ao iniciarem os preparativos para o churrasco de domingo, sendo que na churrasqueira de lata, não existia um espaço por onde a fumaça pudesse desembocar. Então, aquele ambiente esfumaçado deixava quem estava no entorno com um "cheiro de bacon", como disse Cezinha. Percebendo que o convidado também poderia ficar "cheirando a bacon", Cezinha trouxe uma camiseta sua, Monteiro falou que não era necessário sujar uma peça de roupa por esse motivo, mas ele insistiu até que ele a colocasse. Quando apareceu na porta da casa, as duas filhas prontamente reconheceram a vestimenta do pai e brincaram com ele; Andréia também achou engraçado: "olha ali, com a camiseta do Cezinha", disse ela em meio aos risos. Logo em seguida, enquanto espetavam as carnes na cozinha e discutiam sobre o seu alto preço, ao pedir licença para apanhar um talher na gaveta, Cezinha disse: "fica bem à vontade aí, tu é de casa".

Entendemos essa "fusão de horizontes” mencionada por Oliveira (2000) como as tensões, as alegrias, as angústias, os temores, as tramas sociais provenientes das relações que mantemos e partilhamos com os sujeitos durante uma pesquisa antropológica. O fato de "vestir a camiseta" dava a sensação de que o pesquisador estava do mesmo lado deles. Se entendermos a confiança como algo a ser conquistado gradativamente durante uma pesquisa, cremos que essa atitude tenha sido significativa para tornar aquele "estrangeiro" alguém, cada vez mais, "de casa".

O método etnográfico aponta também para uma prática fundamental no sentido de participação, que possibilita ao pesquisador uma aproximação ao objeto. Através da descrição densa ${ }^{39}$, tal como proposta por Geertz (1982), o antropólogo pode

\footnotetext{
${ }^{39}$ Segundo Geertz (1982), a descrição densa é a etnografia, que possibilita ao antropólogo capturar elementos simbólicos que estão na cultura de um povo, sob a forma de estruturas que querem dizer alguma coisa. A tarefa do antropólogo é enfrentar uma multiplicidade de estruturas conceituais complexas, muitas delas sobrepostas ou amarradas umas às outras, que são simultaneamente estranhas, irregulares e inexplícitas. Para isso, o antropólogo deve entrevistar informantes, observar rituais, deduzir os termos de parentesco, traçar as linhas de propriedade, fazer o censo doméstico e escrever o seu diário.
} 
compreender a dinamicidade de criação e uso de certos elementos (simbólicos) culturais. A etnografia é, por excelência, o próprio trabalho do antropólogo e cabe a ele considerar os dados da situação social em que realiza a pesquisa, priorizando as categorias nativas de autodefinição, sem perder de vista que elas são elaboradas em situações de relações sociais que envolvem diferentes grupos e mediadores (Oliveira, 2005).

A complexidade do fazer etnográfico é comparada a "uma tentativa de leitura de um manuscrito estranho, desbotado, cheio de elipses, incoerências, emendas suspeitas e comentários tendenciosos, escrito não com sinais convencionais de som, mas com exemplos transitórios de comportamento modelado" (Geertz, 1982, p. 15-20). É nessa "tentativa de leitura" que se edificam o método etnográfico e a formação do antropólogo. Fazer etnografia é, "ao mesmo tempo, uma arte e uma disciplina científica que consiste em primeiro lugar em saber ver. É em seguida uma disciplina que exige saber estar com outros e consigo mesmo [...] enfim, é uma arte que exige que se saiba retraduzir para um público terceiro e, portanto, que se saiba escrever" (Winkin, 1998, p. 132, grifos do autor). Trata-se de um texto sempre aberto, em construção e diálogo (Marcus \& Cushman, 1982; Marcus, 1995, 1997).

Nesse sentido, a edificação intelectual do antropólogo se torna uma constante construção e desconstrução de noções, pontos de vista, preconceitos, enfim, um aprendizado proporcionado pelo trabalho que vai além de, simplesmente, "estudar o outro", mas "estudar com o outro". Nesse sentido, "a observação é então esta aprendizagem de olhar o outro para conhecê-lo, e ao fazermos isso, também buscamos nos conhecer melhor" (Eckert; Rocha, 2008, p. 3). 


\section{Considerações finais}

Este artigo procurou apresentar e analisar, partindo de uma experiência etnográfica com migrantes quilombolas, quais os dilemas do fazer etnográfico em que o caráter político se apresenta tão fortemente, como a preparação de um laudo antropológico, por exemplo. Observou-se que os moradores e ex-moradores da comunidade remanescente de quilombos Arnesto Penna foram colaboradores ativos no processo de pesquisa, bem como para a possível execução do laudo.

Para os pesquisadores o que se observou deste complexo e delicado processo é que a elaboração de um laudo é um processo coletivo, feito a muitas mãos, composto de muitos saberes e, desta forma, é sempre uma disputa política também. O laudo e seu processo de elaboração são atos políticos por excelência. Desta forma, numa pesquisa em que a convivência com o grupo se manteve após a elaboração do laudo, gerando novo estudo, observou-se o quanto um processo eticamente conduzido gera, não somente uma empatia entre pesquisador e pesquisado, mas também uma maior profundidade na possibilidade de conhecimento do outro, ali transformado em objeto de estudo e de fazer técnico. O laudo antropológico foi um documento legitimou a posição do antropólogo em seu novo contexto de pesquisa.

A descrição das experiências vividas no campo com os quilombolas que migraram do território de origem em Santa Maria para Caxias do Sul mostrou que o fazer etnográfico permitiu encontros, ocasionou contornos e exigiu estratégias. 


\section{Referências}

ABREU, Caio Fernando. Bem longe de Marienbad. In: Estranhos estrangeiros. São

Paulo: Companhia das Letras, 2002, p. 17-42.

ALBERTI, Verena. Um drama em gente: trajetórias e projetos de Pessoa e seus heterônimos. In: SCHMIDT, Benito Bisso (Org.). O biográfico: perspectivas interdisciplinares. Santa Cruz do Sul: Edunisc, 2000, p. 179-241.

ALMEIDA, Alfredo Wagner B. de. Nas bordas da política étnica: os quilombos e as políticas sociais. Boletim Informativo do Nuer, v. 2, n. 2, p. 15-44, 2005.

BARTH, Fredrik. O guru, o iniciador e outras variações antropológicas. Rio de Janeiro: Contra Capa, 2000.

BECKER, Howard. Uma teoria da ação coletiva. Rio de Janeiro: J. Zahar Editor, 1977.

CAMAROFF, John and Jean. Etnography and the historical Imagination. Boulder, Westviews Press, p.3-48, 1992.

CAMUS, Albert. $O$ estrangeiro. Rio de Janeiro: Record, 2006.

CLIFFORD, James. A experiência etnográfica: antropologia e literatura no século XX. 2. ed. Rio de Janeiro: Ed. da UFRJ, 2002.

DUARTE, Luiz Fernando Dias. Da vida nervosa nas classes trabalhadoras urbanas. Rio de Janeiro: J. Zahar Editor, 1986.

ECKERT, Cornelia; ROCHA, Ana Luiza Carvalho da. Etnografia: saberes e práticas. In: PINTO, Céli Regina Jardim; GUAZZELLI, César Augusto Barcellos (Org.). Ciências humanas: pesquisa e método. Porto Alegre: Editora da Universidade, 2008. No prelo.

ELIAS, Norbert. Mozart, sociologia de um gênio. Michael Schröter (Org.). Rio de Janeiro: J. Zahar Editor, 1995.

FABIAN, Johannes. A prática da etnografia como compartilhamento do tempo e como objetivação. Mana, Rio de Janeiro, 2, p.503-520, 2006.

FERREIRA, Ademir Pacelli. O migrante na rede do outro: ensaios sobre alteridade e subjetividade. Rio de Janeiro: Te Corá, 1999.

FONSECA, Claudia. Quando cada caso NÃO é um caso: pesquisa etnográfica e educação. Revista Brasileira de Educação, n. 10, p. 58-78, jan./abr. 1999.

GEERTZ, Clifford. A interpretação das culturas. Rio de Janeiro: LTC, 1982.

GOFFMAN, Erving. A representação do eu na vida cotidiana. 5. ed. Petrópolis: Vozes, 1992.

LEITE, Ilka Boaventura. Questões éticas da pesquisa antropológica na interlocução com o campo jurídico. In: VICTORA, Ceres et al. (Org.). Antropologia e ética: o debate atual no Brasil. Niterói: EdUFF, 2004. p. 73-77.

MARCUS, George e CUSHMAN, Dick. Etnhographies as text. Annual Review of Anthropology 11, p.25-69, 1982. Disponível em www.periodicoscapes.org.br. Acesso em 2011.

MARCUS. George E. Ethnography in/of the world system: the emergence of multi-sited ethnography. Annual Review of Anthropology, 24, p.95-117, 1995. Disponível em www.periodicoscapes.org.br. Acesso em 2011.

MARCUS, George. Identidades passadas, presentes e emergentes: requisitos para etnografias sobre a modernidade no final do século XIX ao nível mundial. Revista de Antropologia/USP, São Paulo, no 34, p. 197-221, 1991.

MARCUS, George. The Uses of Complicity in the Changing Mise-en-Scène of Anthropological Fieldwork. Representations, No. 59, pp. 85-108, summer 1997. Disponível em: http://www.jstor.org/stable/2928816. Acesso em jul 2011

MENEZES, Cláudia. A mudança: análise de um grupo de migrantes. Rio de Janeiro: Imago; Brasília: INL, 1976.

MOCELLIN, Maria Clara. Fluxos migratórios de migrantes urbanos em Caxias do Sul-RS. In:

DUTRA, Delia; MARINUCCI, Roberto; SANTIS, Terezinha (Org.). Vidas em trânsito:

mudanças no percurso migratório de migrantes urbanos. Brasília: CSEM, 2011.

OLIVEIRA, Roberto Cardoso de. O trabalho do antropólogo. São Paulo: Unesp, 2000. 
OLIVEIRA, Osvaldo Martins. O trabalho e o papel do antropólogo nos processos de identificação étnica e territorial. In: LEITE, Ilka Boaventura. (Org.). Laudos periciais antropológicos em debate. Florianópolis: Nuer; ABA, 2005, p. 147-154.

ORTIZ, Renato. O próximo e o distante: Japão e modernidade-mundo. São Paulo: Brasiliense, 2000.

PIRES, André Alves. O estranho estrangeiro e a poética do vestígio em Bem Longe de Marienbad. Literatura em Debate, v. 1, p. 1-14, 2007.

RATTS, Alecsandro J. P. Entre quilombos no litoral, no sertão e na Amazônia: memórias de negros migrantes. In: HEIDEMANN, Heinz Dieter; SILVA, Sidney Antônio da (Org.). Simpósio Internacional Migração: nação, lugar e dinâmicas territoriais. São Paulo: Humanitas, 2007, p. 261-270.

RICOUER, Paul. O si-mesmo como um outro. São Paulo: Papirus, 1991.

SILVA, Vagner Gonçalves da; REIS, Leticia Vidor; SILVA, José Carlos (Org.). Antropologia e seus espelhos: a etnografia vista pelos observados. São Paulo: FFLCH/USP, 1994.

SILVA, Sergio Baptista da; BITTENCOURT JR., Iosvaldyr Carvalho. Etnicidade e territorialidade: o quadro teórico. In: ANJOS, José Carlos Gomes dos; SILVA, Sergio Baptista da (Org.). São Miguel e Rincão dos Martimianos: ancestralidade negra e direitos territoriais. Porto Alegre: Ed. da UFRGS, 2004, p. 21-29.

SIMMEL, Georg. O estrangeiro. Tradução de Mauro Guilherme Pinheiro Koury. Revista Brasileira de Sociologia da Emoção, v. 4, 2005. Disponível em: <http://www.cchla.ufpb.br/grem/SIMMEL.O\%20estrangeiro.Trad.Koury.rbsedez05.pdf>.

Acesso em: 8 ago. 2011.

SCHÜTZ, Alfred O estrangeiro: um ensaio em Psicologia Social. Tradução de Márcio Duarte e Michael Hanke. Revista Geraes, n. 53, p. 117-129, 2003.

SANTOS, Miriam de Oliveira. Bendito é o fruto: festa da uva e identidade entre os descendentes de imigrantes italianos de Caxias do Sul-RS. 2004. 314 f. Tese (Doutorado em Antropologia Social)-Programa de Pós-Graduação em Antropologia Social do Museu Nacional, Rio de Janeiro, 2004.

SAID, Edward. Reflexões sobre o exílio e outros ensaios. São Paulo: Companhia das Letras, 2003.

TAVARES, Fátima Regina Gomes. Schutz e Simmel: sobre os dilemas da condição social do "estrangeiro". Comum, Rio de Janeiro, v. 6, n. 17, p. 78-90, jul./dez. 2001.

WACQUANT, Loïc. Corpo e alma: notas etnográficas de um aprendiz de boxe. Rio de Janeiro: Relume Dumará, 2002.

WACHTEL, Nathan. Deuses e Vampiros. De volta a Chipaya, São Paulo: Edusp, 1996. WINKIN, Yves. A nova comunicação. São Paulo: Papirus, 1998.

Recebido em: 21/03/2015

Aprovado em: 22/05/2015 